\title{
Principles of energy saving in water supply and sewage systems
}

\author{
Nikolay Makisha ${ }^{1 *}$ and Tatiana Kazimirova ${ }^{1}$ \\ ${ }^{1}$ Moscow state university of civil engineering, Yaroslavskoye shosse, 26, Moscow, Russia, 129337
}

\begin{abstract}
In this paper, we consider energy efficiency in the system of water supply and sanitation. Particular attention is paid to energy conservation techniques, stages of implementation. The review of energy conservation methods, a table of classification, taking into account the cost. The work is aimed at further more detailed study of energy efficiency techniques in the water supply and sanitation and their application in the regions of Russia.
\end{abstract}

\section{Introduction}

The development of economy requires among other things the efficient use of energy and resources of all kind. That approach means significant scientific, technical, organizational and human background. Moreover, reduction of energy and material consumption should not decrease the quality and volumes of production $[1,2]$.

\section{Energy saving and energy efficiency}

\subsection{Efficiency raise for thermal energy use}

If housing and municipal services meant the main directions how to increase efficiency of thermal energy use and energy saving potential are as follows [3]:

- Shutdown of inefficient boilers with appropriate load transfer to other boilers;

- Substitution of inefficient boilers by more efficient;

- Use of gas or local fuel boilers instead of oil boilers;

- Use of hot water instead of steam boilers operation mode;

- Scum and snuff removal from heating surface;

- Application of non-reagent water treatment plants;

- Installation of power generation equipments in boiler plants;

- Introduction of automated control system for boiler plants;

- Thermal rehabilitation of living and public buildings;

- Introduction of metering devices, control and regulation of resource consumption.

\footnotetext{
* Corresponding author: nmakisha@gmail.com
} 


\subsection{Energy saving measures}

Energy saving measures can be divided into several groups according to their implementation costs (table 1).

Table 1. Energy saving measures

\begin{tabular}{|c|c|c|}
\hline Cost-free and low cost & Medium costs & High costs \\
\hline $\begin{array}{l}\text { 1.Proper operation of water } \\
\text { supply and sanitation systems in } \\
\text { general and equipments for this } \\
\text { systems in particular; } \\
\text { 2.Change of graphite to Teflon } \\
\text { pump sealing that may } \\
\text { increase lifetime up to } 6 \text { times; } \\
\text { 3. Fittings replacement }\end{array}$ & $\begin{array}{l}\text { 1.Pump operation in economy } \\
\text { mode } \\
\text { 2. Change of pipelines' diameter, } \\
\text { use of polymer pipes } \\
\text { 3. Saving energy and water during } \\
\text { the transition to the circulating } \\
\text { water supply systems } \\
\text { 4.Elimination scurf in the water } \\
\text { supply and sanitation systems } \\
\text { 5.Prevention of water leaks } \\
\text { 6.Control of water consumption } \\
\text { 7. Automated control of operation } \\
\text { 8. Social promotion of water and } \\
\text { energy saving } \\
\text { 9. Analysis of water discharge }\end{array}$ & $\begin{array}{l}\text { 1. Automated system of energy } \\
\text { consumption control } \\
\text { 2. Application of disposal } \\
\text { equipment at waste water } \\
\text { treatment plant } \\
\text { 3. Use of power-saving reserves } \\
\text { in hot water systems. }\end{array}$ \\
\hline
\end{tabular}

\subsubsection{Pump operation in economy mode}

There are some recommendations for realizing this measure [1,4-6]:

- Substitution of pumps with low performance or construction that provides additional losses of energy

- Substitution of pump with inappropriate hydraulic characteristics

- Improvement of pump performance by means of new seals or impeller balancing

- Implementation of automated control of pumping equipment operation to provide best performance

- Adjustment of pump performance by means of frequency-regulated electric drive

- If frequency adjustment is not available pumps can be regulated by means of step switching of parallel installed pumps on and off

- Application of accumulation tanks with level sensors for the systems that are designed for maximum capacity at maximum pressure.

\subsubsection{Pipelines}

If the pipe diameter is increased at $50 \%$, the fluid friction loss can be reduced by $75 \%$. A similar result for energy saving of water supply may be achieved if pipes made from polymers with significantly lower roughness substituted pipes made from traditional materials. As a result, lifetime of pipeline network may increases from 3-10 to 30 years or more. Besides, the hydraulic resistance and the energy costs for pumps operation constant is lower by about $25 \%$ for the same pipe diameter and the water flow rate $[7,8]$.

A transfer from direct flow to circulating water supply for cooling systems of energy and technological equipment reduces water consumption from external sources, and the load on the pumps intake system and wastewater treatment plants.

Another big technological problem for pipelines is scurf removal and leakages. There are special automated systems created and widely introduced for treatment with additives of 
hot or circulation water systems. These systems do not almost change hardness of water and prevent scurf formation

Localization of leakages requires certain labor and technological costs that means special equipment for acoustic search of leaks. Application of water meter devices is an alternative way to control and locate leaks. Going further, consumption control helps to make the water balance, to analyze water schemes and water costs, optimize the cost of water system. All these measures if applied allow the water supply single units performing as a system.

\subsubsection{Major energy saving reserves in domestic hot water and recirculation systems}

Major energy-saving reserves in domestic hot water systems mean:

- Replacement of water heater with low performance for those, which have a smaller overall size and lower heat loss, as well as simplifying their trim line tube. This leads to a decrease in pump power costs for the heating and circulation of heated water in the heat point.

- Installation of variable frequency drives for circulation and feeding pumps in heat points that allow changing the water flow in the system, without opening or closing of existing valves. These devices help to save $10-30 \%$ of electricity.

- Application of balancing valves and water meters that are interlinked and automatically controlled by a dispatching system.

- Significant energy savings reserves are available in the circulation systems, which is discharged into the environment a significant amount of heat energy in many industrial enterprises. The problem of energy saving in the water supply can be solved with the help of heat pumps, which provide the opportunity to return the heat to the production cycle. Such pumps are widely used in Western Europe, USA and Japan [9-11].

\section{Auditing of engineering systems}

The audit of engineering systems has an aim to create a new program (or rework existing) of data collection system and management of engineering networks and objects, as well as the optimization of energy- water saving measures $[12,13]$.

This program should include:

- Reasonable proposals for technical and technological changes in the system of engineering networks and objects, and a comparison with consumption standards (utilities);

- A list of equipment for water supply, sewerage and heating;

- The terms of reference for the design of all proposed innovations;

- Justification and calculation of the payback period of the project;

- Introduction of changes in the basis of the developed technical proposals:

- Changes to the напорных characteristics of the pump and network geometry, based on the results of hydraulic calculations;

- Introduction of variable frequency drives with automatic control and regulation;

- Introduction of modern heat generating and heat exchange devices, and thermal resistance materials;

- Introduction of modern metering and control energy- water recourses. 


\section{Systems of automated control}

Measurement system means the number instruments and other technical devices (components of the measuring system) interconnected in a certain way of measuring to form the measuring channels. Measurement system implements the process of measurement and provides automatic (automated) obtaining of measurement results (expressed by means of numbers or codes corresponding to them), time varying and distributed in the space of physical quantities characterizing certain properties (state) measurement object. The measurement system has the main features of measuring devices and their specific features.

As follows from the definition, the components of the measuring system are technical devices, included into its structure to perform one of the functions of the measurement process: measuring, computing or communications [14, 15].

In that way, the measuring components of measurement system are measuring instruments: indicators, measuring converter, measuring switch.

Automated control system has a structure, which consist of three subsystems:

- Subsystem of primary data collection - the lower level;

- Subsystem of primary processing and storage of information - the middle level;

- Subsystem of processing, display, storage and exchange of information - the upper level.

Structurally subsystem of primary data collection includes conversion devices, which measure the parameters of the environment: flow, pressure, temperature and other. The subsystem of middle level normally means controllers. The subsystem of upper level is a specialized computer system with appropriate software. The exchange of information between the subsystems of the lower and middle levels is carried out by measuring channels. Wired links, isolated or switched telephone lines, radio communications may be implemented as communication channels [16].

Economic efficiency of application of automated control system:

- Ensuring payment for energy resources in strict accordance with the actual amount of their consumption;

- Automated registration of energy resources and the control of their parameters;

- Control of the consumption of all energy sources for a certain time interval: from 5 minutes to several years depending to the limits, technological capacity constraints, pressure, flow and temperature;

- Light and sound alarm to notify that measuring parameters go out of allowed limits for making operational decisions.

As soon as the water supply and sewage system equipped with automated control system the payback period can be estimated to register reduction of water consumption; repair cost for pumps and drives; reduction of malfunctions; increase of intervals between repairs. The return of investments begins after the operating order adjusted and launched.

The implementation of such equipment and projects will start obtaining expected results and solving the tasks set. It will also prove the possibility of brand new organization of administrative services and technical personnel of existing enterprises, aimed at addressing the problems of housing and communal services.

The unified information space helps to solve the problem of instant obtaining of information needed for making responsible technological and economic decisions. It also allows carrying out system analysis of the entire data array. Availability of reliable information will provide accurate records of all consuming resources and costs of consumed energy and water resources. The other important peculiarity of the implementation of equipment and automated systems is ability for to systematic and operational management of equipment capacities that has a direct effect on the energy savings (up to $25-40 \%$ ) [17]. 
Creating local automated control systems at remote objects, the implementation of the security alarm system and video system will free up staff by $20-40 \%$ (a decrease of payment of costs). It becomes possible to plan and develop the housing and communal services, considering the budget revenues and consumers' income; application of economically justified tariffs; provision of actual payment for heat, water and sewage based on metering devices rather than on the "standards of consumption. These results will lead to a significant reduction in the cost of utilities and improve their quality [18].

\section{Conclusions}

As seen above, energy saving in water supply and sanitation should be based on the following measures: registration of heat and water supply, energy costs and reduction of their losses; reduction in energy consumption by the power optimization; reduction of the level of manual operation; equipment performance increase by means of energy saving technologies; evaluation of automated systems for data collection and the engineering networks management; efficient and optimal control of technological objects; public information on energy saving measures implementation.

\section{References}

1. E. Gogina, I. Gulshin, Procedia engineering, 117, 107-113 (2015)

2. A.G. Pervov, A.P. Andrianov, T.P. Gorbunova, A.S. Bagdasaryan, Petroleum chemistry, 55 (10), 879-886 (2015)

3. I. Gulshin, A. Kuzina, International Journal of Applied Engineering Research, 10, 21, 42618-42623 (2015)

4. A. Volkov, V. Chulkov, R. Kazaryan, M. Fachratov, O. Kyzina, R. Gazaryan, Applied mechnics and materials, 580-583, 2281-2284, (2014)

5. N. Makisha, A. Kulakov, MATEC web of conferences, 112, 10018 (2017)

6. A.G. Pervov, A.P. Andrianov, E.B. Yurchevskiy, Petroleum chemistry, 55 (10), 871 878 (2015)

7. E. Gogina, A. Pelipenko, MATEC Web of Conferences, 73, 03007 (2016)

8. V.N. Varapaev, S.A. Doroshenko, A.Y. Trotsko, A.V. Doroshenko, International Journal of Applied Engineering Research, 10, 21, 42588-42592 (2015)

9. O. Kuzina, E. Pankratov, V. Tkachev, MATEC Web of Conferences, 86, 05023 (2016)

10. V. Orlov, A. Andrianov, Applied mechanics and materials, 580-583, 2398-2402 (2014)

11. V.N. Varapaev, A.V. Doroshenko, I.Y. Lantsova, Procedia engineering, 153, 816-823 (2016)

12. N. Makisha, M.Yunchina, MATEC Web of Conferences, 106, 70016 (2017)

13. A.G. Pervov, A.P. Andrianov, Desalination and water treatment, 35 (1-3), 2-9 (2011)

14. E. Gogina, I. Gulshin, Applied mechanics and materials, 580-583, 2367-2369 (2014)

15. Volkov, O. Kuzina, Procedia engineering, 153, 838-843 (2016)

16. A.A. Volkov, A.V. Sedov, P.D. Chelyshkov, D.A. Lysenko, A.V. Doroshenko, International Journal of Applied Engineering Research, 10, 22, 43269-43272 (2015)

17. E. Gogina, I. Gulshin, Procedia engineering, 153, 189-194 (2016) 
18. A.G. Pervov, A.P. Andrianov, V.A. Chukhin, R.V. Efremov, International Journal of Applied Engineering Research, 10, 22, 43517-43525 (2015) 